\title{
Positive Modulation of Pink Nelumbo nucifera Flowers on Memory Impairment, Brain Damage, and Biochemical Profiles in Restraint Rats
}

\author{
Thawatchai Prabsattroo, ${ }^{1,2}$ Jintanaporn Wattanathorn, ${ }^{2,3}$ \\ Pichet Somsapt, $^{4}$ and Opass Sritragool ${ }^{4}$ \\ ${ }^{1}$ Department of Physiology and Graduate School (Neuroscience Program), Faculty of Medicine, Khon Kaen University, \\ Khon Kaen 40002, Thailand \\ ${ }^{2}$ Integrative Complementary and Alternative Medicine Research and Development Center, Khon Kaen University, \\ Khon Kaen 40002, Thailand \\ ${ }^{3}$ Department of Physiology, Faculty of Medicine, Khon Kaen University, Khon Kaen 40002, Thailand \\ ${ }^{4}$ Division of Nuclear Medicine, Department of Radiology, Faculty of Medicine, Khon Kaen University, Khon Kaen 40000, Thailand
}

Correspondence should be addressed to Jintanaporn Wattanathorn; jintanapornw@yahoo.com

Received 30 June 2015; Revised 30 August 2015; Accepted 31 August 2015

Academic Editor: Felipe Dal Pizzol

Copyright (C) 2016 Thawatchai Prabsattroo et al. This is an open access article distributed under the Creative Commons Attribution License, which permits unrestricted use, distribution, and reproduction in any medium, provided the original work is properly cited.

Due to the crucial role of oxidative stress in the stress-induced memory deficit, the benefit of substance possessing antioxidant effect is focused. Since no data are available, we aimed to determine the effect of Nelumbo nucifera flowers extract on spatial memory and hippocampal damage in stressed rats. Male Wistar rats, weighing 250-350 g, were orally given N. nucifera extract at doses of 10,10 , and $200 \mathrm{mg} \cdot \mathrm{kg}^{-1} 45$ minutes before the exposure to 12 -hour restraint stress. The spatial memory and serum corticosterone were assessed at 7 and 14 days of study period. At the end of study, acetylcholinesterase (AChE), monoamine oxidase type A and monoamine oxidase type B (MAO-A and MAO-B), oxidative stress status, neuron density, and Ki67 expression in hippocampus were also assessed. The results showed that $N$. nucifera extract decreased memory deficit and brain damage, serum corticosterone, oxidative stress status, $\mathrm{AChE}$, and MAO-A and MAO-B activities but increased neuron density and Ki67 expression in hippocampus. These suggested that the improved oxidative stress status, adult neurogenesis, and cholinergic and monoaminergic functions might be responsible for the protective effect against stress-related brain damage and dysfunction of the extract. Therefore, $N$. nucifera extract is the potential neuroprotective and memory enhancing agent. However, further researches are still required.

\section{Introduction}

Daily stress produces a great burden on neuropsychological problems including cognitive impairment. Stress can stimulate the responses via the hypothalamic-pituitary-adrenocortical (HPA) axis and the sympathetic-adrenomedullary (SAM) system. It has been reported that stress increases the monoaminergic system functions with a subsequent increase in oxidative stresses [1] and memory impairment [2]. In addition, the stimulation of HPA axis induced by stresses also gives rise to the elevation of glucocorticoids (GCs) leading to dendritic atrophy and neurodegeneration in the $\mathrm{CA} 3$ region together with the suppression of neurogenesis in dentate gyrus of hippocampus [3]. It has been reported that the prevalence of memory impairment is increased in company with the increased daily stress exposure. Unfortunately, no current drugs can prevent brain damage and memory impairment induced by stress. Therefore, effective neuroprotective agent against this condition is required. A substantial evidence has demonstrated that substances possessing antioxidant activity can prevent the brain damage [4-6] and memory deficit $[4,7]$ induced by stress. Therefore, the protective effect against stress-related brain damage and dysfunctions of medicinal plant possessing antioxidant activity has been considered. 
Nelumbo nucifera Gaertn or sacred water lotus is belonging to the family of Nymphaeaceae. It is widely used in the indigenous system of medicine of many countries. It is also used as health beverages for treating hypertension, cancer, diarrhea, fever, weakness, infection, and body heat imbalance [8]. In vitro data show that the flower extract of $N$. nucifera exhibits antioxidant activity [9]. Based on its antioxidant effect, we hypothesized that the flower extract of $N$. nucifera might mitigate brain damage and memory impairment induced by stress. Therefore, we aimed to determine the protective effect of $N$. nucifera flower extract on memory and hippocampal damage. The possible underlying mechanism was also investigated.

\section{Materials and Methods}

2.1. Plant Materials and Preparation. Flowers of N. nucifera were harvested during November-December 2012 from Khon Kaen province, Thailand. N. nucifera were authenticated by Dr. Nopachai Chansilp, Rajamangala University of Technology Tawan-ok. The herbarium specimen was deposited at Integrative Complementary Alternative Medicine Research and Development Center, Khon Kaen University, after the authentication. The flowers were cleaned, cut into small pieces, dried in oven at $40^{\circ} \mathrm{C}$, and ground into powder. Then, the powder was extracted with $50 \%$ hydroalcoholic solvent by maceration technique and filtered through Whatman filter paper number 1 . The filtrate was concentrated with rotator evaporator at $45^{\circ} \mathrm{C}$ and kept at $4^{\circ} \mathrm{C}$ until being used. The percentage yield of the extract was $10.23 \%$. The finger print chromatogram of $N$. nucifera showed that the total phenolic compounds and quercetin concentrations were $152.963 \pm$

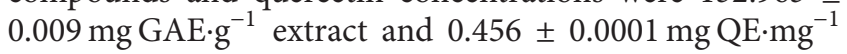
extract, respectively, as shown in Figure 1.

2.2. Animal Treatment. Adult male Wistar rats, weighing 250-350 g, were purchased from National Laboratory Animal Center, Salaya, Nakhon Pathom province. They were housed, six per cage, under standard conditions and maintained under a 12:12 dark-light cycle. Temperature was controlled at $24 \pm 1^{\circ} \mathrm{C}$. Food and water were available ad libitum throughout the experiments.

2.3. Experimental Protocol. Male rats at the age of $8-12$ weeks were trained for learning and memory for 7 days. The trained animals were divided into various groups ( $n=6$ /group) as described below.

Group I. It is naïve control (nontreated group).

Group II. Vehicle plus stress: rats were orally given distilled water 45 minutes before being subjected to $12 \mathrm{~h}$ restraint stress exposure.

Group III. Tianeptine: rats were orally given Tianeptine at dose of $15 \mathrm{mg} \cdot \mathrm{kg}^{-1} 45$ minutes before being subjected to $12 \mathrm{~h}$ restraint stress exposure. (Tianeptine was previously shown to improve memory impairment induced by stress [10] so it was used as positive control.)

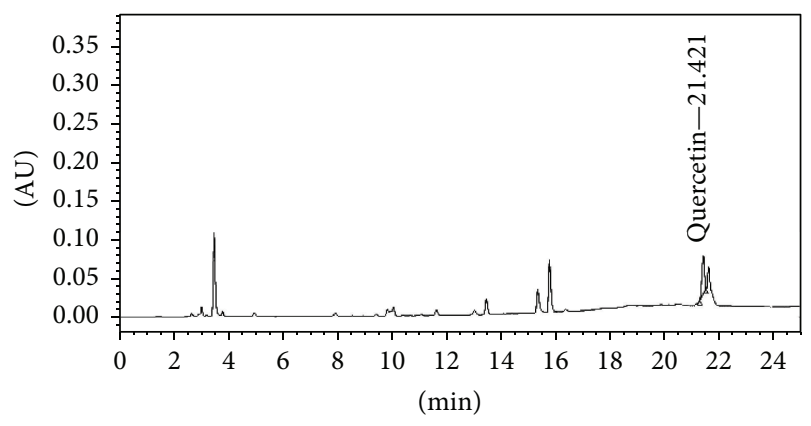

Figure 1: The fingerprint chromatogram of $50 \%$ hydroalcoholic extract of Nelumbo nucifera flowers used in this study.

Groups IV-VI. N. nucifera flowers extract treated groups: rats were orally given hydroethanolic extract of $N$. nucifera extract at doses of 10,100 , and $200 \mathrm{mg} \cdot \mathrm{kg}^{-1} 45$ minutes before being subjected to $12 \mathrm{~h}$ restraint stress exposure. (These doses were selected based on our pilot data.)

The assigned treatments were carried out once daily throughout a 14-day study period. The determination of spatial memory and serum corticosterone was performed every 7 days until the end of study period. The biochemical changes including malondialdehyde (MDA) level and the activities of superoxide dismutase (SOD), catalase (CAT), glutathione peroxidase (Glu-Px), acetylcholinesterase (AChE), monoamine oxidase type A (MAO-A) and monoamine oxidase type B (MAO-B), and the expression of Ki67 (adult proliferation marker) together with the histopathological changes in hippocampus were also evaluated at the end of study.

2.4. Determination of Spatial Memory. In this part, the animals' spatial memory was assessed by using Morris water maze test. The circular pool $(170 \mathrm{~cm}$ in diameter $\times 58 \mathrm{~cm}$ in length) was divided into 4 quadrants and filled with water $\left(25^{\circ} \mathrm{C}, 40 \mathrm{~cm}\right.$ depth $)$. The water surface was covered with nontoxic milk powder. The removable platform was immersed under the surface water in one of the quadrants. Each rat was trained to memorize the location of an invisible platform by forming the association between its location and the location of a platform by using external cues. The time the animals spent swimming to find the hidden platform was recorded as escape latency. Twenty-four hours later, the animals were reexposed to the same condition except that the platform was removed in order to assess the capability to retrieve and retain information and recoded as retention time.

2.5. Corticosterone Assay. Blood was collected and kept on ice at 7 and 14 days of study period. Then, it was centrifuged immediately at $2000 \times \mathrm{g}$ at $4^{\circ} \mathrm{C}$ for $15 \mathrm{~min}$. The obtained serum was kept at $-80^{\circ} \mathrm{C}$ until being used. Corticosterone levels were measured using Corticosterone Double Antibody Radioimmunoassay Kit (MP Biomedicals). The results were showed as $\mathrm{ng} / \mathrm{mL}$. 
2.6. Determination of Acetylcholine Esterase (AChE) Activity. After the isolation, hippocampus was homogenized with sodium phosphate buffer (0.1 M, pH 7.4) and centrifuged at $14000 \times \mathrm{g}$ at $4^{\circ} \mathrm{C}$ for $20 \mathrm{~min}$. The supernatant was harvested and used for the determinations of AChE activity and protein concentrations by Ellman et al. [11] and Lowry methods [12], respectively.

\subsection{Determination of Monoamine Oxidase A and B Activities.} The activities of monoamine oxidase type $A$ and monoamine oxidase type $\mathrm{B}$ (MAO-A and MAO-B) were evaluated by the continuous peroxidase-linked photometric assay according to the method of Holt et al. [13] with some modifications. Hippocampus was homogenized and centrifuged at $14000 \times \mathrm{g}$, at $4^{\circ} \mathrm{C}$ for $20 \mathrm{~min}$. After the centrifugation, the supernatant was harvested for the determination of MAO-A and MAO-B activities. In brief, $40 \mu \mathrm{L}$ of brain homogenate was incubated with the mixture containing $120 \mu \mathrm{L}$ amino substrate $(2.5 \mathrm{mM}$ tyramine (Sigma-Aldrich) in potassium phosphate buffer), $40 \mu \mathrm{L}$ chromogenic solution (1 mM vanillic acid, $0.5 \mathrm{mM} \mathrm{4-}$ aminoantipyrine, and $4 \mathrm{U} / \mathrm{mL}$ peroxidase in potassium phosphate buffer) for $30 \mathrm{~min}$ at $37^{\circ} \mathrm{C}$. The 30 -minute preincubation of brain homogenate with either pargyline or clorgyline at $37^{\circ} \mathrm{C}$ was carried out to determine MAO-A or MAO$B$ activity. The reactions were assessed by using microplate reader at $490 \mathrm{~nm}$.

2.8. Determination of Oxidative Stress Markers. Hippocampal homogenate was prepared using sodium phosphate buffer $(0.1 \mathrm{M}, \mathrm{pH} 7.4)$ and subjected to the 15 -minute centrifugation at $4^{\circ} \mathrm{C}$ for $15 \mathrm{~min}$. Then, the supernatant was collected and used for the determination of oxidative stress markers including MDA level and the activities of SOD, CAT, and GSHPx. SOD activity was determined via McCord and Fridovich method [14] whereas CAT and GSH-Px activities were determined via the method of Chance and Maehly [15] and the method of Rotruck et al. [16], respectively. SOD, CAT, and GSH-Px activities were expressed as unit. $\mathrm{mg}^{-1}$ protein. In addition MDA level was also determined by using thiobarbituric acid (TBA) assay [17] and expressed as nmol. $\mathrm{mg}^{-1}$ protein.

2.9. Cresyl Violet Staining. At the end of experiment, brains were isolated after the transcardial perfusion with NSS and postfixed with $4 \%$ paraformaldehyde in $0.1 \mathrm{M}$ phosphate buffer $\mathrm{pH} 7.4$ at $4^{\circ} \mathrm{C}$ overnight. Then, they were immersed in cryoprotectant containing $30 \%$ sucrose for $48-72 \mathrm{~h}$. Brains were cut at $10 \mu \mathrm{m}$ thickness and picked up on slides coated with a $0.01 \%$ aqueous solution of gelatin. The serial sections were stained with $0.5 \%$ cresyl violet. Six coronal sections from each rat in each group were studied quantitatively. Neuronal counts were performed by eye using a $40 \mathrm{x}$ magnification with final field $255 \mu \mathrm{m}^{2}$ and Bregma coordination according to the following stereotaxic coordinates: AP $-4.8 \mathrm{~mm}$, lateral $\pm 2.4-$ $6 \mathrm{~mm}$, and depth $3-8 \mathrm{~mm}$. The observer was blinded to the treatment at the time of analysis. Counts were made in five adjacent fields and the mean number extrapolated to give total number of neurons per $255 \mu \mathrm{m}^{2}$.
2.10. Determination of Ki67 by Western Blotting. Hippocampus was isolated and prepared as homogenate by using ice cold RIPA buffer with protease inhibitors. The homogenate was subjected to the $14,000 \times \mathrm{g}$ centrifugation at $4^{\circ} \mathrm{C}$ for 20 minutes. The supernatant was harvested and we measured the level of protein by using NANO drop Spectrophotometers. Equal amounts of protein $(50 \mu \mathrm{g})$ were fractionated by $8 \%$ SDS polyacrylamide gel electrophoresis and transferred to a polyvinylidene difluoride membrane (Bio-Rad Laboratories, Hercules, CA). Each step was preceded by three times rinsing with the solution containing $0.05 \%$ Tris-buffer saline with Tween-20 for 5 minutes each. Membranes were blocked with $5 \%$ skim milk in Tris-buffer saline with $0.05 \%$ Tween-20 and incubated with the primary antibody against Ki67, a proliferative marker $(1: 500)$, overnight. After this process, the membranes were incubated with horseradish peroxidase-linked secondary antibody $(1: 4,000)$ for 1 hour at room temperature. Then the signal was enhanced with a Thermo Scientific Pierce ECL Substrate chemiluminescence kit (Pierce ECL Western Blotting) [18]. Images were acquired by ImageQuant LAS 4000, GE Healthcare. Band densities were quantified with NIH-ImageJ (Version 1.48V; National Institutes of Health, USA). The PVDF was reprobed with the beta actin antibody $(1: 2,000)$ as a loading control.

2.11. Statistical Analysis. Data were expressed as mean \pm S.E.M. The significance of differences among the groups was assessed using one-way analysis of variance (ANOVA) test followed by LSD multiple comparison test using SPSS, version 13. In addition, repeated measures ANOVA was used to analyze escape latency and retention time within group at various treatment durations. Moreover, paired $t$-test analysis was implemented on corticosterone level. $P$ value $<0.05$ was considered as significance.

\section{Results}

3.1. Effect of N. nucifera Flowers Extract on Spatial Memory. Figure 2 showed that rats that are subjected to restraint stress and received vehicle or water significantly increased escape latency after a single dose of administration and this change was still observed both at 7 and at 14 days of treatment $(P$ value $<0.001$ all, compared with naïve control group). Tianeptine attenuated the increased escape latency in restraint stress rats throughout the study period $(P$ value $<$ 0.001 all, compared with vehicle + stress treated group). It was found that rats which received $N$. nucifera at all doses and are exposed to $12 \mathrm{~h}$ restraint stress significantly decreased escape latency after a single-dose administration and the changes were still observed at 7 and 14 days of treatment $(P$ value $<$ 0.001 , compared to vehicle + stress). In addition, repeated measures ANOVA was also determined to observe the time effect on escape latency and retention time after restraint stress at the various treatment durations. It was found that no effect of treatment duration on escape latency was observed.

Figure 3 showed that rats which were exposed to $12 \mathrm{~h}$ restraint stress and received vehicle decreased the retention time after a single dose of administration and both at 7 and at 14 days of treatment $(P$ value $<0.05,0.001$, and 0.01 , 


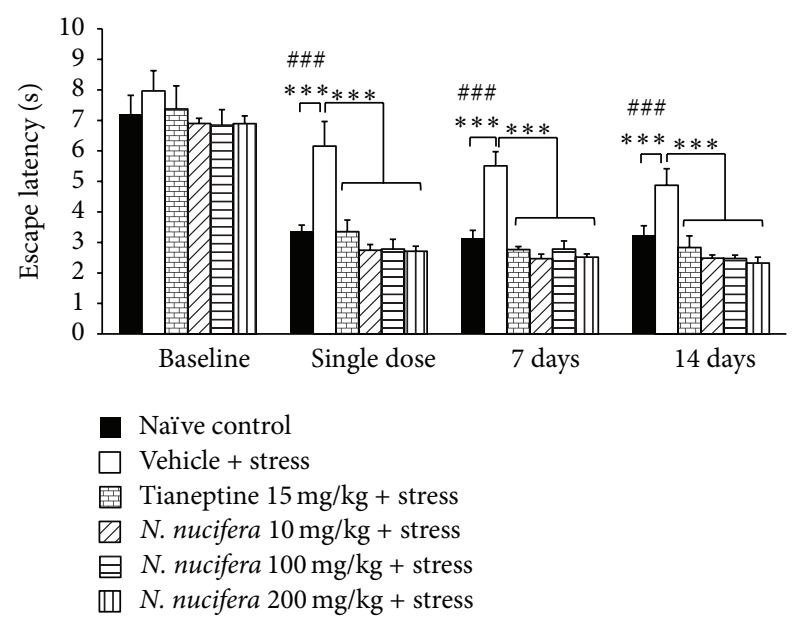

Figure 2: The effect of hydroalcoholic extracts of N. nucifera flowers extract on escape latency of stress-exposed rats at baseline, after a single dose, and at 7 days and 14 days of treatment. Data were expressed as mean \pm S.E.M. $(n=6$ /group $) .{ }^{* * *} P$ value $<0.001$, compared with vehicle plus stress. ${ }^{\# \#} P$ value $<0.001$, respectively, compared with control group.

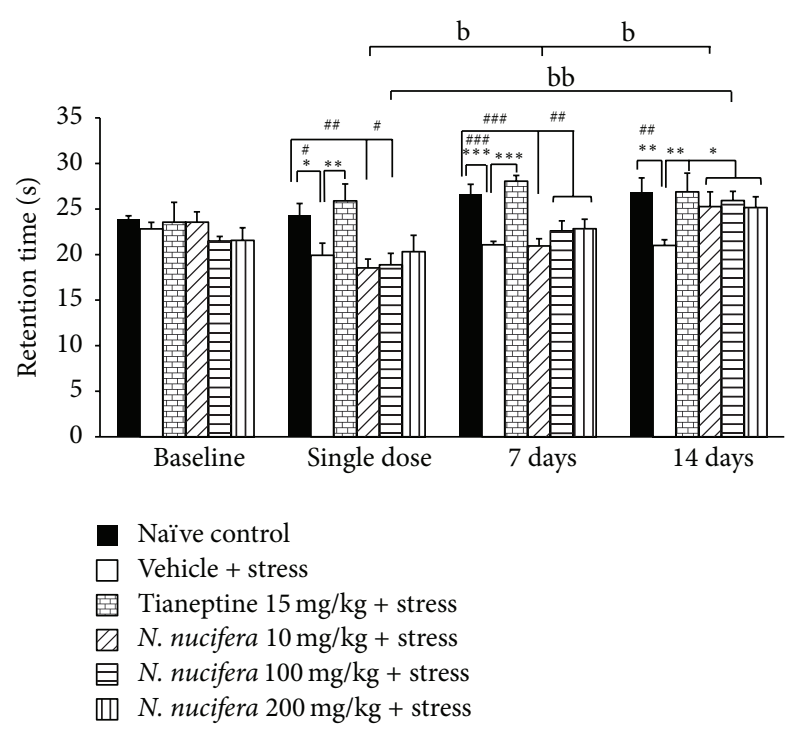

FIgURE 3: The effect of hydroalcoholic extracts of $N$. nucifera flowers extract on retention time of stress-exposed rats at baseline, after a single dose, and at 7 days and 14 days of treatment. Data were expressed as mean \pm S.E.M. $\left(n=6\right.$ /group). ${ }^{*, * *, * * *} P$ value $<$ $0.05,0.01$, and 0.001 , respectively, compared with vehicle plus stress. $\#, \#, \#$.\#\# value < $0.05,0.01$, and 0.001 , respectively, compared with control group. ${ }^{\mathrm{b}, \mathrm{bb}} P$ value $<0.05$ and 0.01 , respectively, compared with the retention time of the single-dose treatment within each group.

resp., compared with naïve control group). Tianeptine could mitigate the reduction of retention time in restraint rats $(P$ value $<0.01$ all, compared with vehicle + stress treated group). Interestingly, all doses of $N$. nucifera used in this study could mitigate the reduction of retention time in restraint rats ( $P$ value $<0.05$ all, compared to vehicle + stress $)$ at 14

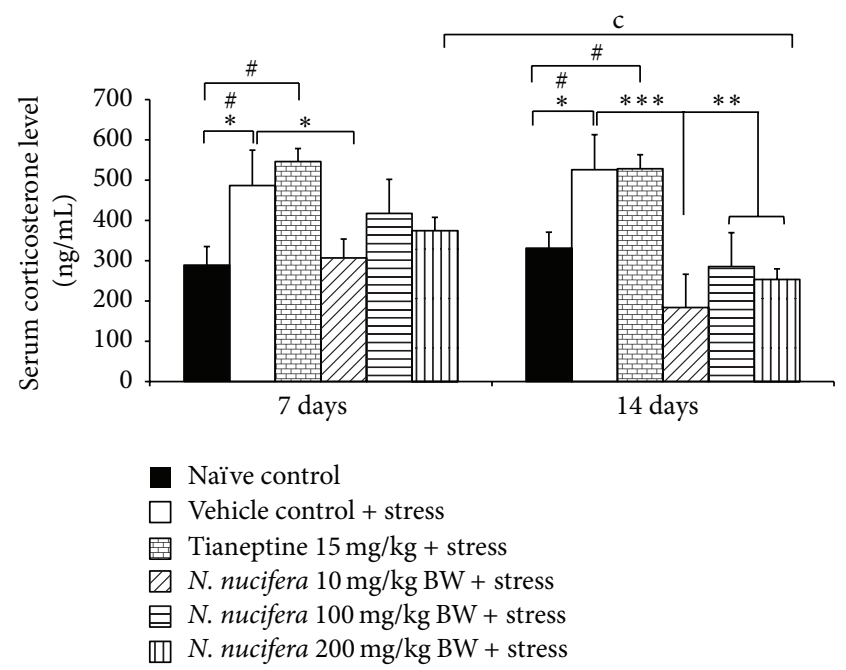

FIGURE 4: The effect of hydroalcoholic extracts of $N$. nucifera flowers extract on serum corticosterone levels of stress-exposed rats at 7 days and 14 days of treatment. Data were expressed as mean \pm S.E.M. ( $n=5$ /group). ${ }^{*, * *, * * *} P$ value $<0.05,0.01$, and 0.001 , respectively, compared with vehicle plus stress. ${ }^{\#} P$ value $<0.05$, compared with control group. ${ }^{\mathrm{c}} P$ value $<0.05$, compared with the serum corticosterone level at 7 days of treatment within each group.

days of experimental period. It was found that the increased treatment duration to 7 and 14 days enhanced the retention time in rats which received stress and low dose of $N$. nucifera extract more than the retention time of this treatment group which was observed after the single-dose treatment $(P$ value $<$ 0.05 all, compared with the retention time of the single-dose treatment within the same group). However, no significant difference change was observed regarding the effect of the low dose extract on retention time at 7 and 14 days of treatment. The rats subjected to stress and medium dose of $N$. nucifera also significantly increased the retention time when the treatment was prolonged further to 14 days of treatment $(P$ value $<0.01$, compared with the retention time of the singledose treatment within the same group). No other effects of treatment duration on retention time were observed.

\subsection{Effect of N. nucifera Flowers Extract on Serum Corticos-} terone Level. Rats which received vehicle and repetitive stress exposure significantly increased serum corticosterone levels both at 7 and at 14 days of exposure time $(P$ value $<0.05$ all, compared to naïve control) as shown in Figure 4. Tianeptine failed to modulate the elevation of serum corticosterone in stress-exposed rats. $N$. nucifera flowers extract at low dose mitigated the elevation of serum corticosterone in stressexposed rats at 7 and 14 days of exposure time $(P$ value $<$ 0.05 and 0.001 , resp., compared to vehicle + stress). Stressexposed rats which received the extract at doses of 100 and $200 \mathrm{mg} \cdot \mathrm{kg}^{-1} \mathrm{BW}$ significantly mitigated the elevation of this parameter when the exposure time was prolonged to 14 days $(P$ value $<0.05$ all, compared to vehicle + stress $)$. In addition, paired $t$-test was also determined to evaluate the effect of treatment duration on corticosterone level. It was 
TABLE 1: Effect of N. nucifera leaves extract on oxidative stress markers (SOD, GSH-Px, CAT, and MDA).

\begin{tabular}{|c|c|c|c|c|}
\hline Group & $\begin{array}{c}\text { SOD } \\
\text { unit/mg.protein }\end{array}$ & $\begin{array}{c}\text { GSH-Px } \\
\text { unit/mg.protein }\end{array}$ & $\begin{array}{c}\text { CAT } \\
\text { unit/mg.protein }\end{array}$ & $\begin{array}{c}\text { MDA } \\
\mathrm{nmol} / \mathrm{mg} \cdot \text { protein }\end{array}$ \\
\hline Naïve control & $2.6 \pm 0.5^{* * *}$ & $13.5 \pm 0.6^{* * *}$ & $38.1 \pm 5.4^{*}$ & $0.19 \pm 0.02^{* * *}$ \\
\hline Vehicle + stress & $0.5 \pm 0.1^{\# \# \#}$ & $2.9 \pm 0.2^{\# \# \#}$ & $18.2 \pm 5.5^{\#}$ & $0.66 \pm 0.08^{\# \# \#}$ \\
\hline Tianeptine $15 \mathrm{mg} / \mathrm{kg}$ + stress & $2.8 \pm 0.3^{* * *}$ & $13.5 \pm 0.5^{* * *}$ & $23.9 \pm 5.3$ & $0.23 \pm 0.01^{* * *}$ \\
\hline N. nucifera $10 \mathrm{mg} / \mathrm{kg}+$ stress & $1.0 \pm 0.5^{\# \#}$ & $2.8 \pm 0.1^{\# \#}$ & $32.0 \pm 5.6^{*}$ & $0.09 \pm 0.00^{* * *}$ \\
\hline N. nucifera $100 \mathrm{mg} / \mathrm{kg}+$ stress & $0.7 \pm 0.2^{\# \#}$ & $2.8 \pm 0.2^{\# \# \#}$ & $32.2 \pm 2.1^{*}$ & $0.09 \pm 0.00^{* * *}$ \\
\hline N. nucifera $200 \mathrm{mg} / \mathrm{kg}+$ stress & $0.5 \pm 0.2^{\# \# \#}$ & $2.8 \pm 0.1^{\# \# \#}$ & $36.3 \pm 3.3^{*}$ & $0.09 \pm 0.01^{* * *}$ \\
\hline
\end{tabular}

${ }^{*, * * *} P<0.05$ and 0.001 , respectively, compared to vehicle plus stress.

$\#, \#, \# \# P<0.05,0.01$, and 0.001 , respectively, compared to naïve control.

found that when the treatment was prolonged to 14 days of treatment, rats which received high dose of $N$. nucifera showed a significant reduction of serum corticosterone from that of the 7-day treatment $(P$ value $<0.05$, compared with 7 days within group). No significant differences were observed in other treatment groups.

\subsection{Effect of N. nucifera Flowers Extract on Acetylcholinester-} ase Activity. Figure 5 showed that rats subjected to restraint stress significantly increased AChE activity in hippocampus ( $P$ value $<0.001$, compared to naïve control). Tianeptine attenuated the increased AChE activity in restraint stress rats $(P$ value $<0.01$, compared to vehicle + stress $)$. It was found that $N$. nucifera flowers extract at all doses significantly decreased AChE activity in restraint stress rats $(P$ value $<$ 0.001 all, compared to vehicle + stress).

\subsection{Effect of N. nucifera Flowers Extract on Monoamine Oxi-} dase-A and Monoamine Oxidase-B. Rats which received vehicle and were subjected to restraint stress significantly increased the activity of both MAO-A and MAO-B in hippocampus ( $P$ value $<0.001$ all, compared to naïve control). Tianeptine mitigated the elevation of both MAO-A and MAO-B ( $P$ value $<0.001$ all, compared to vehicle + stress). Rats that were subjected to restraint stress and received $N$. nucifera flowers extract at all doses significantly decreased MAO-A and MAO-B activities in hippocampus ( $P$ value $<$ 0.001 all, compared to vehicle + stress) as shown in Figure 6 .

\subsection{Effect of N. nucifera Flowers Extract on Oxidative Stress} Markers. Table 1 showed that repetitive restraint stress which received vehicle significantly decreased SOD, CAT, and GSHPx activities but increased MDA level in hippocampus ( $P$ value $<0.001,0.05,0.001$, and 0.001 , resp., compared to naïve control group). Rats which received Tianeptine plus stress significantly increased SOD and GSH-Px activities but decreased MDA level in hippocampus $(P$ value < 0.001 all, compared to vehicle + stress). All doses of $N$. nucifera significantly decreased MDA level in hippocampus ( $P$ value $<0.001$ all, compared to vehicle + stress) but they failed to produce the significant changes on SOD and GSHPx activities in hippocampus of stress-exposed rats. However, the medium and high doses of $N$. nucifera increased CAT

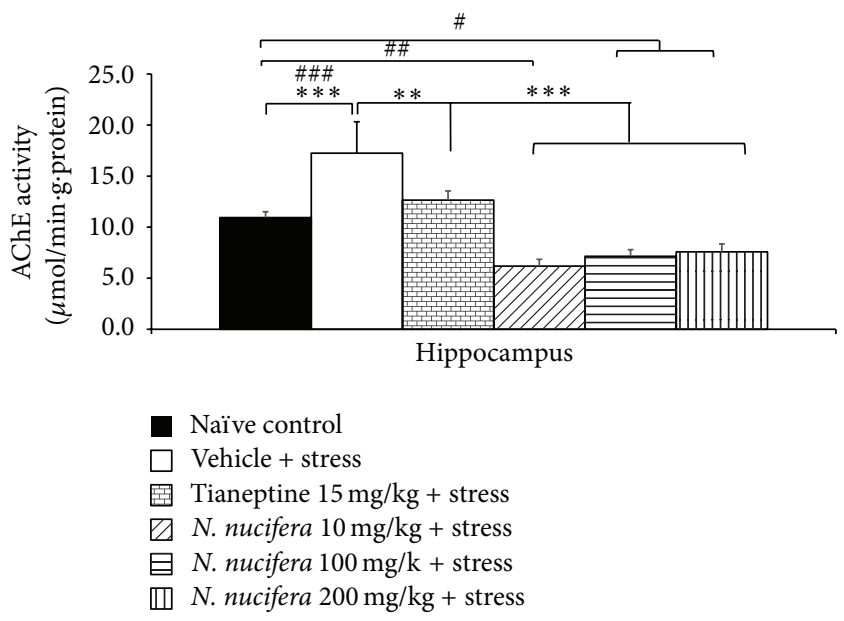

FIGURE 5: The effect of hydroalcoholic extracts of $N$. nucifera flowers extract on acetylcholinesterase activity in hippocampus of stressexposed rats. Data were expressed as mean \pm S.E.M. ( $n=6 /$ group $)$. ${ }^{* * * * * *} P$ value $<0.01$ and 0.001 , respectively, compared with vehicle

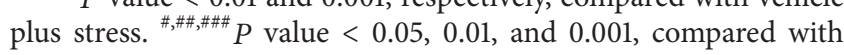
control group.
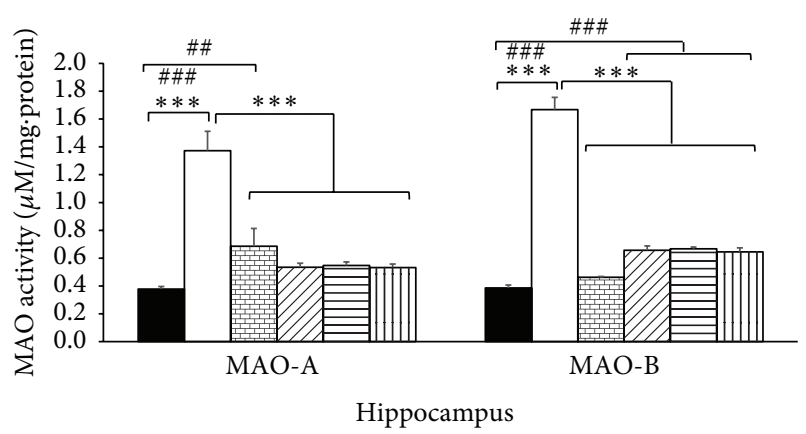

Hippocampus

Naïve control

Vehicle + stress

徳 Tianeptine $15 \mathrm{mg} / \mathrm{kg}+$ stress

$\square$ N. nucifera $10 \mathrm{mg} / \mathrm{kg}+$ stress

目 N.nucifera $100 \mathrm{mg} / \mathrm{kg}+$ stress

ㅁ. N. nucifera $200 \mathrm{mg} / \mathrm{kg}+$ stress

FIGURE 6: The effect of hydroalcoholic extracts of $N$. nucifera flowers extract on monoamine oxidase type A and monoamine oxidase type $B$ of stress-exposed rats. Data were expressed as mean \pm S.E.M. $\left(n=6\right.$ /group). ${ }^{* * *} P$ value $<0.001$, respectively, compared with

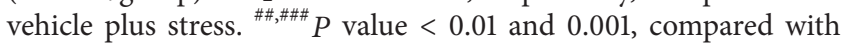
control group. 

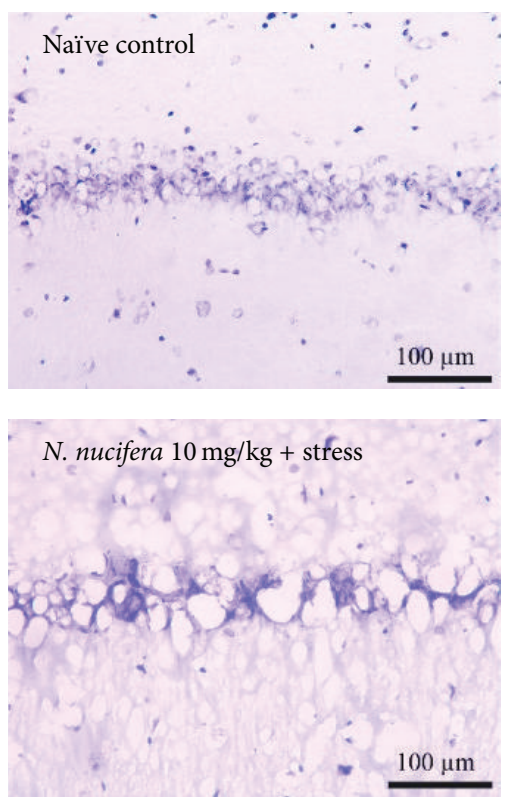
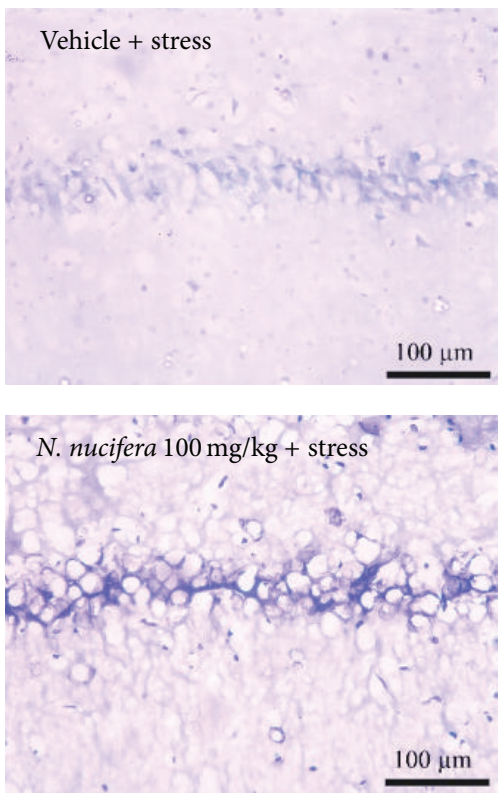
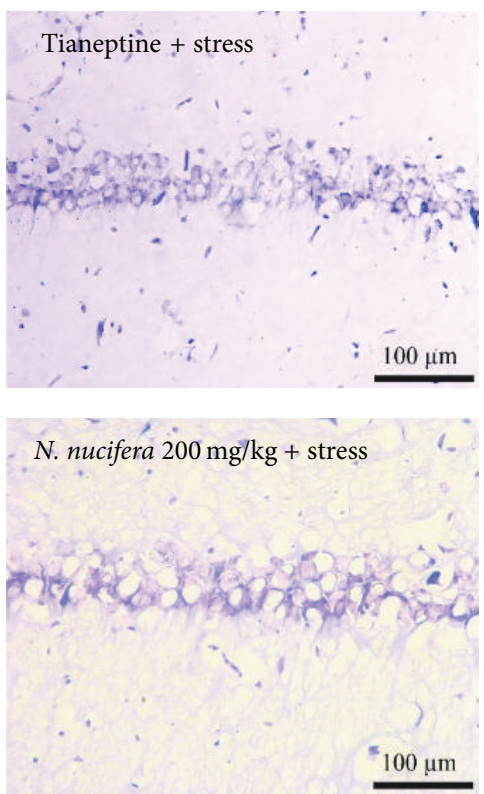

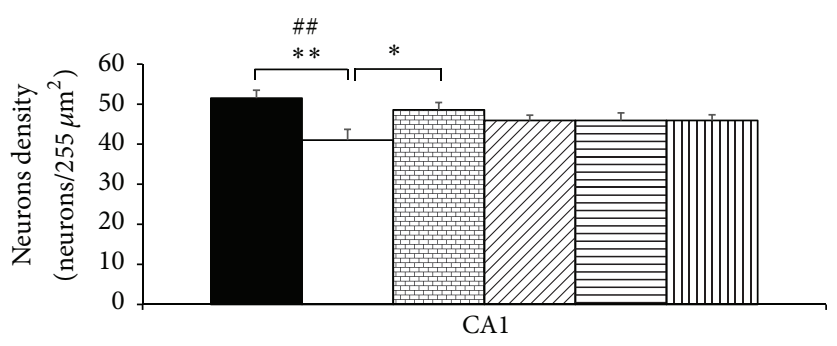

$\square$ Naïve control
$\square$ Vehicle + stress
Tianeptine $15 \mathrm{mg} / \mathrm{kg}+$ stress
$\square$ N. nucifera $10 \mathrm{mg} / \mathrm{kg}+$ stress
目 Nucifera $100 \mathrm{mg} / \mathrm{kg}+$ stress
m. N. nucifera $200 \mathrm{mg} / \mathrm{kg}+$ stress

Figure 7: The effect of hydroalcoholic extracts of N. nucifera flowers extract on the density of survival neurons in CA1 of hippocampus of stress-exposed rats. Data were expressed as mean \pm S.E.M. $(n=6$ /group $) .{ }^{* * *} P$ value $<0.05$ and 0.01 , respectively, compared with vehicle plus stress. ${ }^{\#} P$ value $<0.01$, compared with control group.

activity ( $P$ value $<0.05$ all, compared to vehicle + stress) in hippocampus of stress-exposed rats.

\subsection{Effect of N. nucifera Flowers Extract on Survival Neurons} in Hippocampus. It was found that rats which obtained vehicle plus stress showed the decreased neurons density in CA1, CA2, CA3, and dentate gyrus $(P$ value $<0.01,0.01$, 0.05 , and 0.01 , resp., compared to naïve control). Tianeptine increased neuron density in all areas mentioned earlier in stress-exposed rats $(P$ value $<0.05,0.01,0.01$, and 0.05 , resp., compared to vehicle + stress). Interestingly, $N$. nucifera flowers extract at doses of 10,100 , and $200 \mathrm{mg} / \mathrm{kg}$ produced the significant increase in neurons density in CA2 $(P$ value $<$ $0.05,0.05$, and 0.001 , resp., compared to vehicle + stress) and CA3 ( $P$ value $<0.01,0.01$, and 0.001 , resp., compared to vehicle + stress) of stressed rats. Low dose of N. nucifera produced the significant increase of neurons density in dentate gyrus ( $P$ value $<0.05$, compared to vehicle + stress) as shown in Figures 7-10. No significant changes were observed in CA1 at all doses of N. nucifera.

3.7. Effect of N. nucifera Flowers Extract on Ki67 Proliferative Marker. Figure 11 showed that repetitive exposure to restraint stress significantly decreased the level of Ki67, an adult neurogenesis marker, in hippocampus of stress-exposed rats ( $P$ value $<0.05$, compared with naïve control). Tianeptine and $N$. nucifera extract at doses of 100 and $200 \mathrm{mg} / \mathrm{kg}$ failed to produce the change of Ki67 level in hippocampus of stressexposed rats. However, stress-exposed rats which received $N$. nucifera extract at dose of $10 \mathrm{mg} / \mathrm{kg}$ could increase Ki67 level 

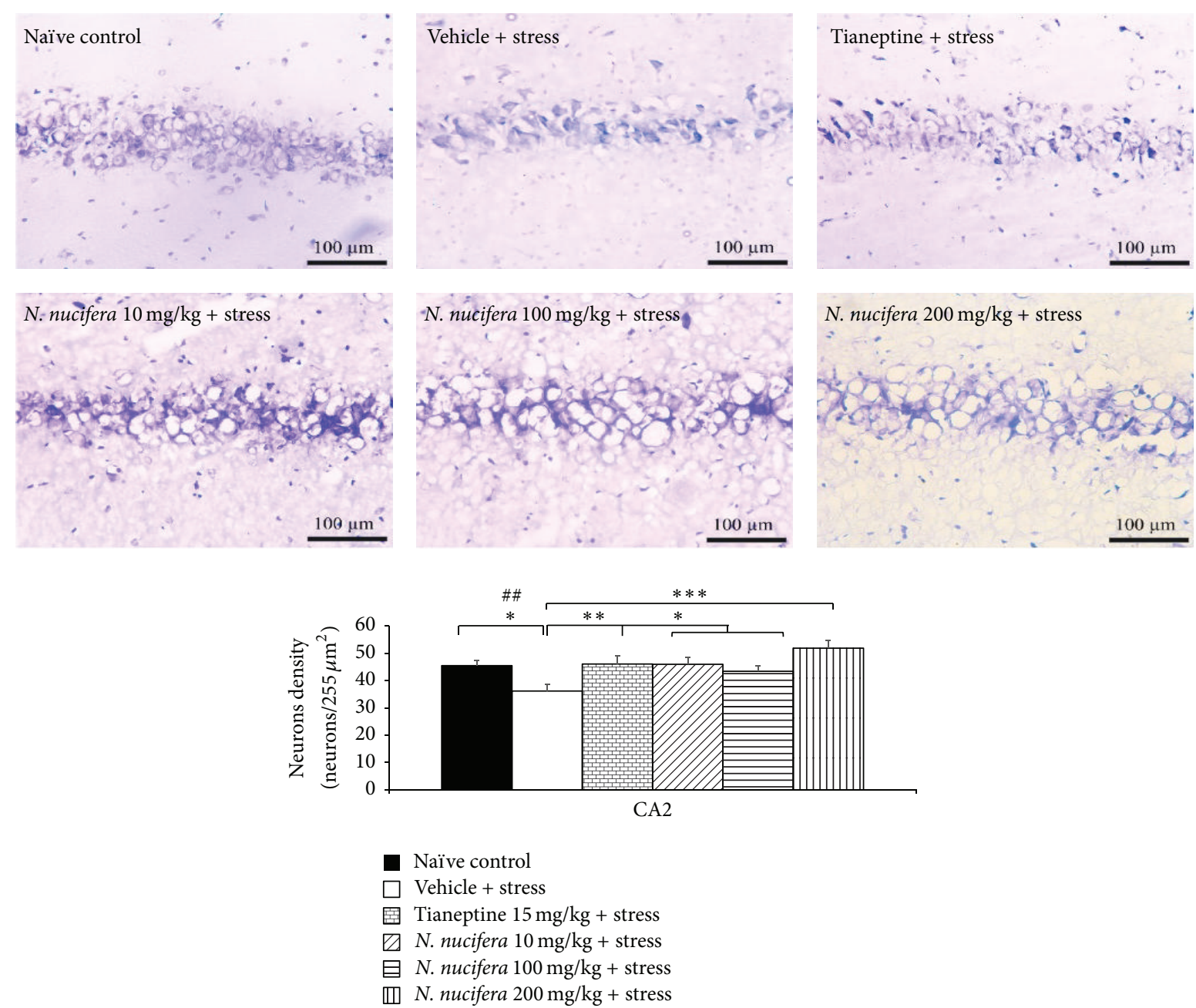

Figure 8: The effect of hydroalcoholic extracts of $N$. nucifera flowers extract on the density of survival neurons in CA2 of hippocampus of stress-exposed rats. Data were expressed as mean \pm S.E.M. ( $n=6$ /group). ${ }^{*, * * * * *} P$ value $<0.05,0.01$, and 0.001 , respectively, compared with vehicle plus stress. ${ }^{\# \#} P$ value $<0.01$, compared with control group.

in the mentioned area $(P$ value $<0.05$, compared to vehicle + stress).

\section{Discussion}

It has been well known that hippocampus is a heterogeneous structure. Various subregions of hippocampus perform different functions. CA3 is preferentially involved in acquisition, consolidation, and retention phase of memory [1921] whereas $C A 1$ is involved in retention and retrieval of memory $[19,20]$ and dentate gyrus (DG) is important for encoding [20]. It has been recently shown that CA2 plays minor role in spatial memory but it plays an important role in social memory and social recognition [22]. In addition, hippocampus is also recognized as the special area at which neurogenesis can occur throughout adult lives [23]. Recent findings have shown that adult neurogenesis plays role in learning and memory [24].

Various processes of learning and memory depend not only on area specificity of hippocampus but also on various types of neurotransmitters. It has been shown that acetylcholine is essential for the encoding process, the first phase of memory, and dopamine plays the crucial role in both acquisition and retention of memory [25]. Norepinephrine is also implicated in hippocampus-based learning and memory especially acquisition process via adrenergic receptor [26].

The data obtained from this study demonstrated that the stress-exposed rats which received $N$. nucifera flowers extract at all doses used in this study showed the enhanced neuron density in CA2 and CA3 in hippocampus together with the improved spatial memory and the suppression effects of 

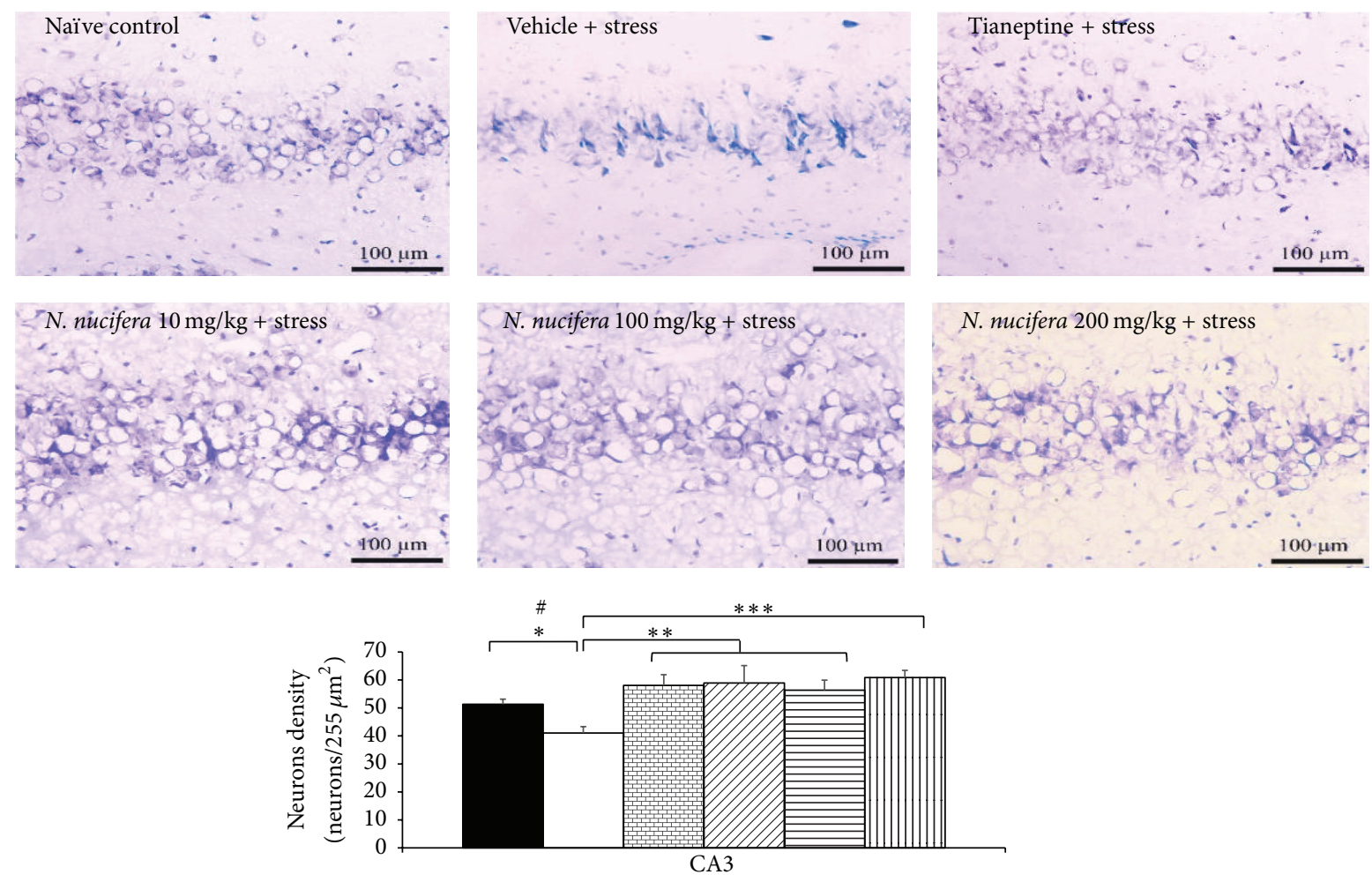

Naïve control

$\square$ Vehicle + stress

團 Tianeptine $15 \mathrm{mg} / \mathrm{kg}+$ stress

Ð N. nucifera $10 \mathrm{mg} / \mathrm{kg}+$ stress

目 N. nucifera $100 \mathrm{mg} / \mathrm{kg}+$ stress

四 N. nucifera $200 \mathrm{mg} / \mathrm{kg}+$ stress

FIGURE 9: The effect of hydroalcoholic extracts of $N$. nucifera flowers extract on the density of survival neurons in CA3 of hippocampus of stress-exposed rats. Data were expressed as mean \pm S.E.M. $(n=6 /$ group $) .{ }^{*, * * * * *} P$ value $<0.05,0.01$, and 0.001 , respectively, compared with vehicle plus stress. ${ }^{\#} P$ value $<0.05$, compared with control group.

AChE, MAO-A, and MAO-B. On the basis of the information mentioned earlier, it has been suggested that the memory enhancing effect of $N$. nucifera flowers extract may occur partly via the increased neuron density in CA3 which in turn increases the acquisition, consolidation, and memory retention of memory leading to the improved spatial memory. In addition, $N$. nucifera flowers extract may also suppress $\mathrm{AChE}$ and both types of MAO resulting in the increased available ACh, NE, and DA in hippocampus which in turn increase encoding process and retention of memory and finally give rise to the improved memory.

In this study, the decreased serum corticosterone levels and the decreased oxidative stress status were also observed in rats that were subjected to $12 \mathrm{~h}$ immobilization stress and received $N$. nucifera flowers extract at all doses used in this study. The decreased serum corticosterone might increase the neurons density in hippocampus via the decreased excitotoxicity induced by corticosterone in hippocampus [27]. Besides the decreased serum corticosterone, the decreased oxidative stress in hippocampus also has important role in the increased density of survival neurons in the mentioned area. Although the oxidative stress status was very much improved, only the elevation of CAT activity was observed. Therefore, other factors such as the increased nonenzymatic antioxidant activity and the decreased oxidative stress formation might also have the role in the reduction of MDA level. N. nucifera flowers extract also increased Ki67 expression which in turn indicated the increased hippocampal neurogenesis in stressexposed rats which received low dose $\left(10 \mathrm{mg} \cdot \mathrm{kg}^{-1} \mathrm{BW}\right)$ of extract. Therefore, besides the mechanisms just mentioned, the increased neurons density in hippocampus in stressexposed rats which received low dose of $N$. nucifera might be attributed to the increased adult neurogenesis in hippocampus.

The current study failed to show the dose dependent effect. The possible explanation might be attributed to the masking effect of other ingredients presented in the extract. In addition, the observed parameters were under the influence 

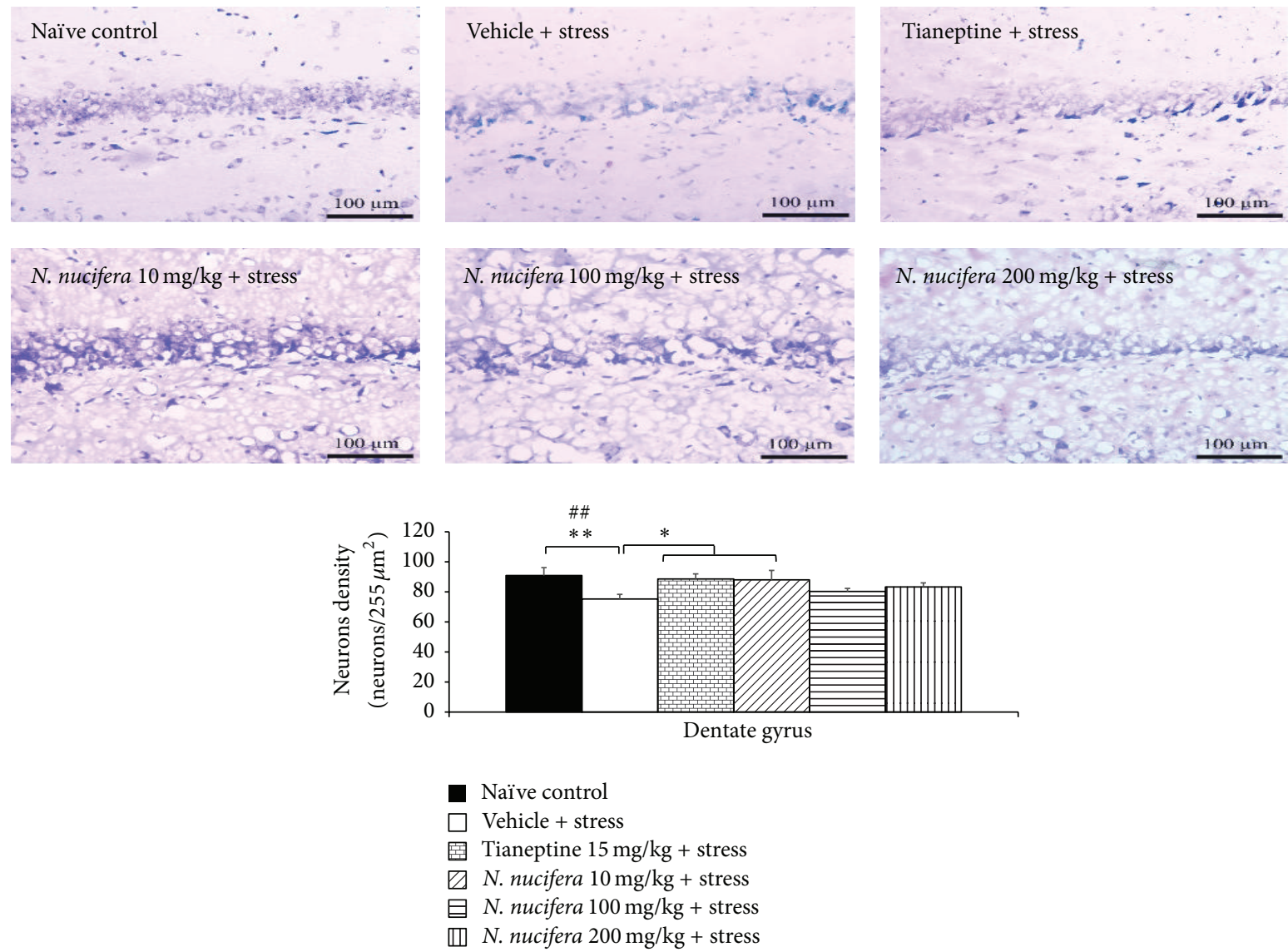

Figure 10: The effect of hydroalcoholic extracts of $N$. nucifera flowers extract on the density of survival neurons in dentate gyrus of hippocampus of stress-exposed rats. Data were expressed as mean \pm S.E.M. ( $n=6 /$ group). ${ }^{*, * *} P$ value $<0.05$ and 0.01 , respectively, compared with vehicle plus stress. ${ }^{\# P}$ value $<0.05$, compared with control group.

of many factors so no single relationship and dose dependent effect were observed. The effect of treatment duration was observed only on the change of retention time of the low dose treatment group but not in other groups. This might possibly occur because the change of retention time induced by the medium and high doses of extract had already achieved the maximum change and cannot produce any more change.

\section{Conclusion}

$N$. nucifera flowers extract was the potential neuroprotective and cognitive enhancer agent against stress-related brain damage and memory deficit. The possible underlying mechanisms are associated with the improved oxidative stress status, the increased adult neurogenesis, and the increased neurotransmitters which play the role in learning and memory such as acetylcholine, dopamine, and norepinephrine. They can also provide benefits as neuroprotectant and memory enhancer against stress-induced memory deficit. In addition, most of them are not expensive and easy to approach.
Therefore, they may serve as the potential neuroprotective and memory enhancing agent. However, further researches concerning the active ingredient, pharmacokinetics, and drug interaction are essential before moving to the clinical trial.
Abbreviations
N. Nucifera: Nelumbo nucifera
AChE: Acetylcholine esterase
MAO-A: Monoamine oxidase type A
MAO-B: Monoamine oxidase type B
GSH-Px: Glutathione peroxidase
SOD: $\quad$ Superoxide dismutase
CAT: $\quad$ Catalase
MDA: Malondialdehyde.

\section{Conflict of Interests}

The authors declare that there is no conflict of interests. 


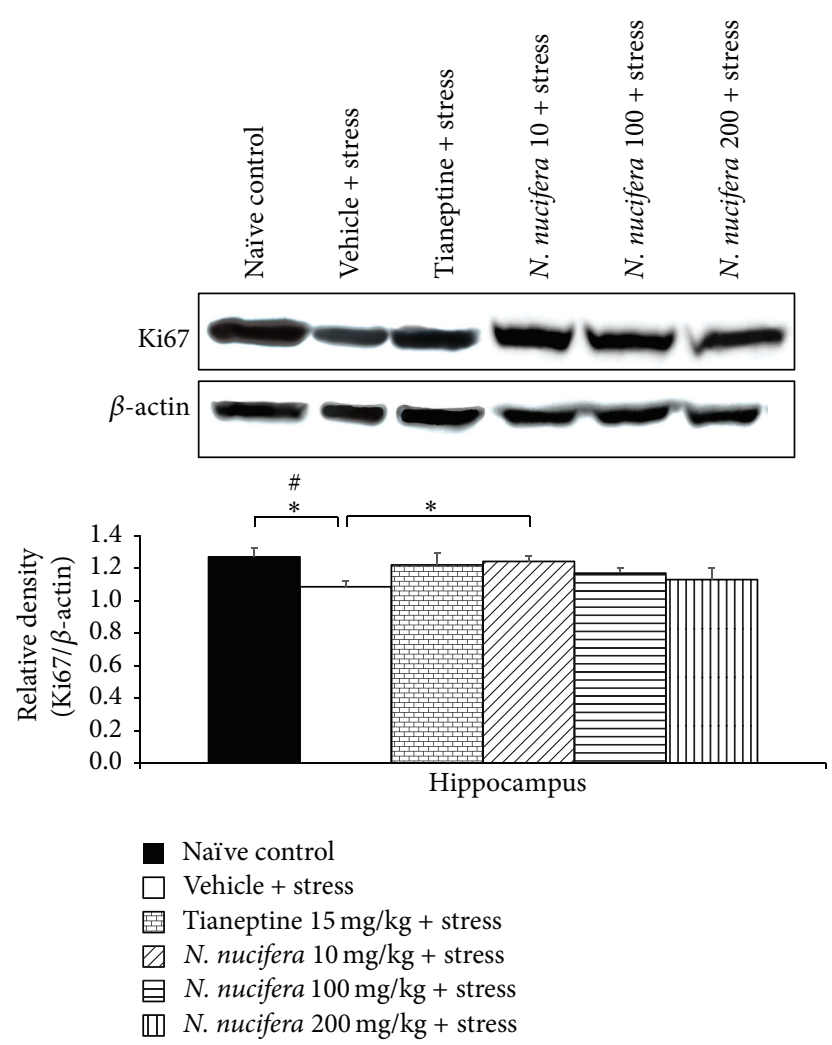

Figure 11: The effect of hydroalcoholic extracts of $N$. nucifera flowers extract on Ki67 proliferative marker of stress-exposed rats. Data were expressed as mean \pm S.E.M. $(n=6 /$ group $) .{ }^{*} P$ value $<0.05$, compared with vehicle plus stress. ${ }^{\#} P$ value $<0.05$, compared with control group.

\section{Acknowledgments}

This study was supported by The National Research Council of Thailand (NRCT), the Higher Education Research Promotion and National Research University Project of Thailand, Office of the Higher Education Commission, through the Food and Functional Food Research Cluster of Khon Kaen University, and The Integrative Complementary Alternative Medicine Research and Development Center, Khon Kaen University, Thailand.

\section{References}

[1] A. Ahmad, N. Rasheed, N. Banu, and G. Palit, "Alterations in monoamine levels and oxidative systems in frontal cortex, striatum, and hippocampus of the rat brain during chronic unpredictable stress," Stress, vol. 13, no. 4, pp. 355-364, 2010.

[2] Y. Liu, X. Zhuang, L. Gou et al., "Protective effects of nizofenone administration on the cognitive impairments induced by chronic restraint stress in mice," Pharmacology Biochemistry and Behavior, vol. 103, no. 3, pp. 474-480, 2013.

[3] B. S. McEwen, "Stress and hippocampal plasticity," Annual Review of Neuroscience, vol. 22, pp. 105-122, 1999.

[4] R. S. Kumar, S. N. Narayanan, and S. Nayak, "Ascorbic acid protects against restraint stress-induced memory deficits in wistar rats," Clinics, vol. 64, no. 12, pp. 1211-1217, 2009.
[5] Y. J. Lee, B. Choi, E. H. Lee, K. S. Choi, and S. Sohn, "Immobilization stress induces cell death through production of reactive oxygen species in the mouse cerebral cortex," Neuroscience Letters, vol. 392, no. 1-2, pp. 27-31, 2006.

[6] A. Ahmad, N. Rasheed, K. Chand, R. Maurya, N. Banu, and G. Palit, "Restraint stress-induced central monoaminergic \& oxidative changes in rats \& their prevention by novel Ocimum sanctum compounds," The Indian Journal of Medical Research, vol. 135, no. 4, pp. 548-554, 2012.

[7] A. Kumar and R. Goyal, "Quercetin protects against acute immobilization stress-induced behaviors and biochemical alterations in mice," Journal of Medicinal Food, vol. 11, no. 3, pp. 469-473, 2008.

[8] C. Saengkhae, W. Arunnopparat, and P. Sungkhajorn, "Antioxidative activity of the leaf of Nelumbo nucifera Gaertn. on oxidative stress-induced erythrocyte hemolysis in hypertensive and normotensive rats," Thai Journal of Physiological Sciences, vol. 20, pp. 70-78, 2007.

[9] B. Durairaj and A. Dorai, "Antiplatelet activity of white and pink Nelumbo nucifera Gaertn flowers (White and Pink)," Brazilian Journal of Pharmaceutical Sciences, vol. 46, no. 3, pp. 579-583, 2010.

[10] Y. Watanabe, E. Gould, D. C. Daniels, H. Cameron, and B. S. McEwen, "Tianeptine attenuates stress-induced morphological changes in the hippocampus," European Journal of Pharmacology, vol. 222, no. 1, pp. 157-162, 1992.

[11] G. L. Ellman, K. D. Courtney, V. Andres Jr., and R. M. Featherstone, "A new and rapid colorimetric determination of acetylcholinesterase activity," Biochemical Pharmacology, vol. 7, no. 2, pp. 88-90, 1961.

[12] O. H. C. Lowry, N. J. Rosebrough, A. L. Farr, and R. J. Randall, "Protein measurement with the Folin phenol reagent," The Journal of Biological Chemistry, vol. 193, no. 1, pp. 265-275, 1951.

[13] A. Holt, D. F. Sharman, G. B. Baker, and M. M. Palcic, "A continuous spectrophotometric assay for monoamine oxidase and related enzymes in tissue homogenates," Analytical Biochemistry, vol. 244, no. 2, pp. 384-392, 1997.

[14] J. M. McCord and I. Fridovich, "Superoxide dismutase. An enzymic function for erythrocuprein (hemocuprein)," Journal of Biological Chemistry, vol. 244, no. 22, pp. 6049-6055, 1969.

[15] B. Chance and A. C. Maehly, "Assay of catalases and peroxidases," Methods in Enzymology, vol. 2, pp. 764-775, 1955.

[16] J. T. Rotruck, A. L. Pope, H. E. Ganther, A. B. Swanson, D. G. Hafeman, and W. G. Hoekstra, "Selenium: biochemical role as a component of glatathione peroxidase," Science, vol. 179, no. 4073, pp. 588-590, 1973.

[17] M. Uchiyama and M. Mihara, "Determination of malonaldehyde precursor in tissues by thiobarbituric acid test," Analytical Biochemistry, vol. 86, no. 1, pp. 271-278, 1978.

[18] M. A. Titheradge, Nitric Oxide Protocols, vol. 100, Humana Press, New York, NY, USA, 1998.

[19] I. Lee and R. P. Kesner, "Different contributions of dorsal hippocampal subregios to emory acquisation and retrieval in contextual fear-conditioning," Hippocampus, vol. 14, no. 3, pp. 301310, 2004.

[20] I. Lee and R. P. Kesner, "Encoding versus retrieval of spatial memory: double dissociation between the dentate gyrus and the perforant path inputs into CA3 in the dorsal hippocampus," Hippocampus, vol. 14, no. 1, pp. 66-76, 2004. 
[21] H.-A. Steffenach, R. S. Sloviter, E. I. Moser, and M.-B. Moser, "Impaired retention of spatial memory after transection of longitudinally oriented axons of hippocampal CA3 pyramidal cells," Proceedings of the National Academy of Sciences of the United States of America, vol. 99, no. 5, pp. 3194-3198, 2002.

[22] D. A. Caruana, G. M. Alexander, and S. M. Dudek, "New insights into the regulation of synaptic plasticity from an unexpected place: hippocampal area CA2," Learning and Memory, vol. 19, no. 9, pp. 391-400, 2012.

[23] G. Kempermann, H. G. Kuhn, and F. H. Gage, "Genetic influence on neurogenesis in the dentate gyrus of adult mice," Proceedings of the National Academy of Sciences of the United States of America, vol. 94, no. 19, pp. 10409-10414, 1997.

[24] J.-S. Kim, J. Jung, H.-J. Lee et al., "Differences in immunoreactivities of Ki-67 and doublecortin in the adult hippocampus in three strains of mice," Acta Histochemica, vol. 111, no. 2, pp. 150156, 2009.

[25] W. C. da Silva, C. C. Köhler, A. Radiske, and M. Cammarota, " $\mathrm{D}_{1} / \mathrm{D}_{5}$ dopamine receptors modulate spatial memory formation," Neurobiology of Learning and Memory, vol. 97, no. 2, pp. 271-275, 2012.

[26] M. J. Gertner and S. A. Thomas, "The role of norepinephrine in spatial reference and spatial working memory," College Undergraduate Research Electronic Journal, p. 18, 2006.

[27] I. M. Ábrahám, T. Harkany, K. M. Horvath, and P. G. M. Luiten, "Action of glucocorticoids on survival of nerve cells: promoting neurodegeneration or neuroprotection?" Journal of Neuroendocrinology, vol. 13, no. 9, pp. 749-760, 2001. 


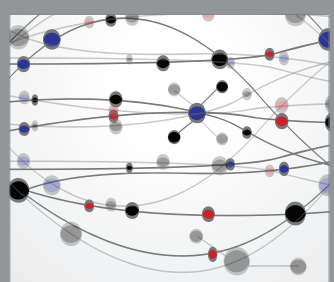

The Scientific World Journal
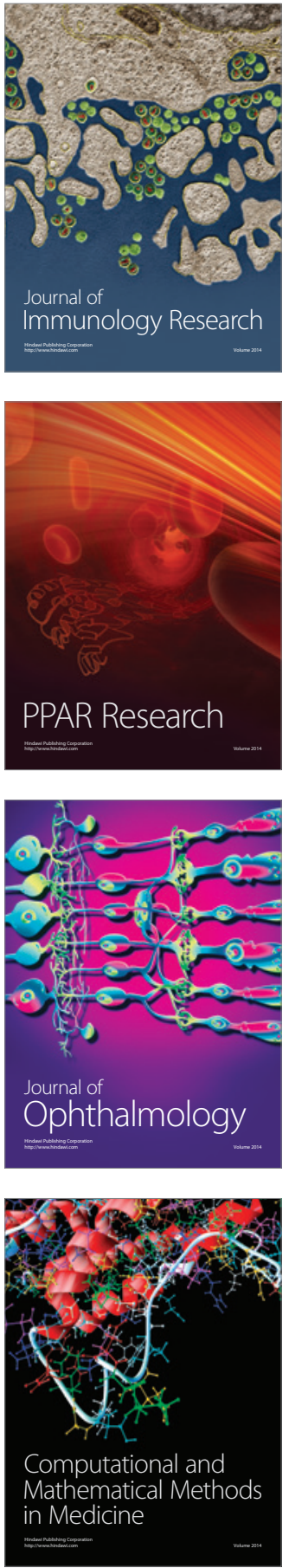

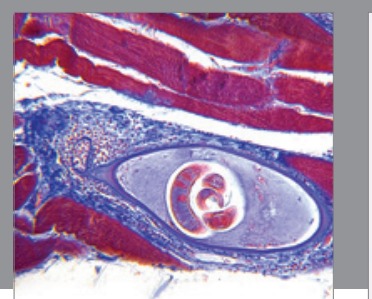

Gastroenterology Research and Practice

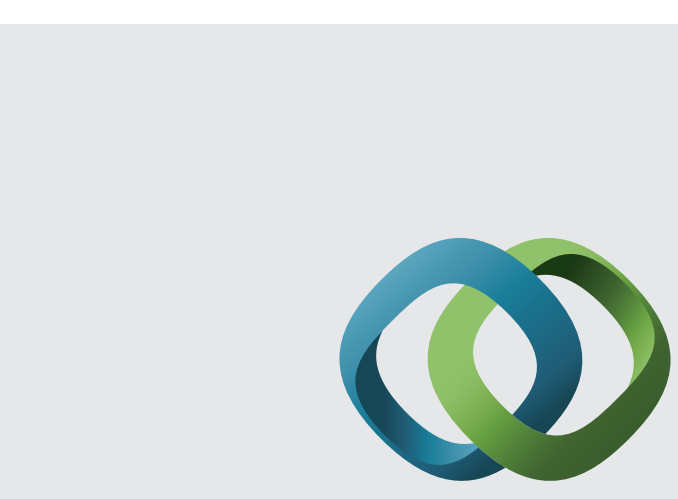

\section{Hindawi}

Submit your manuscripts at

http://www.hindawi.com
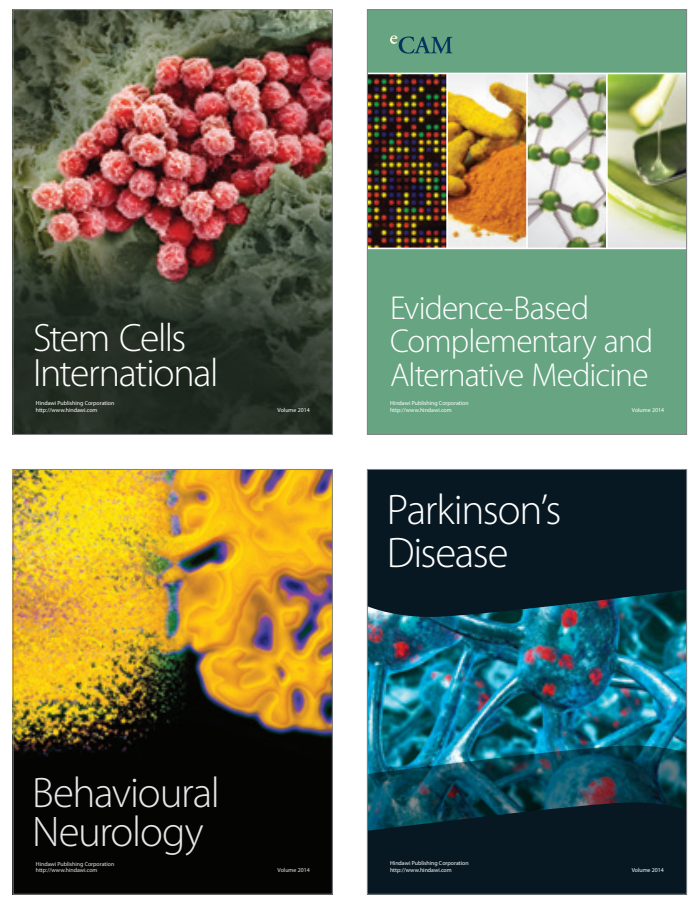
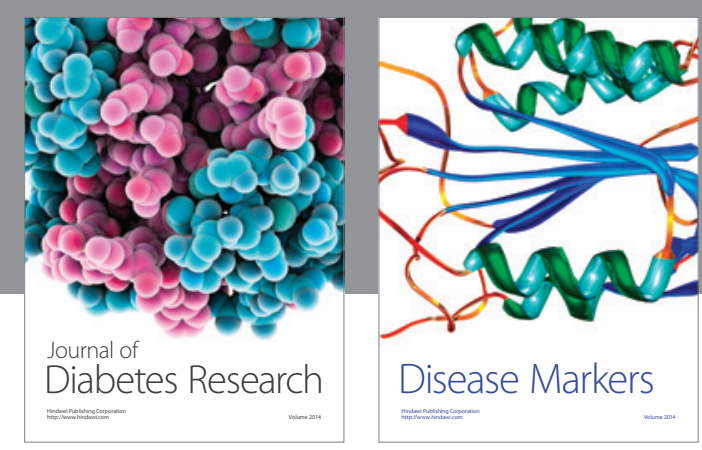

Disease Markers
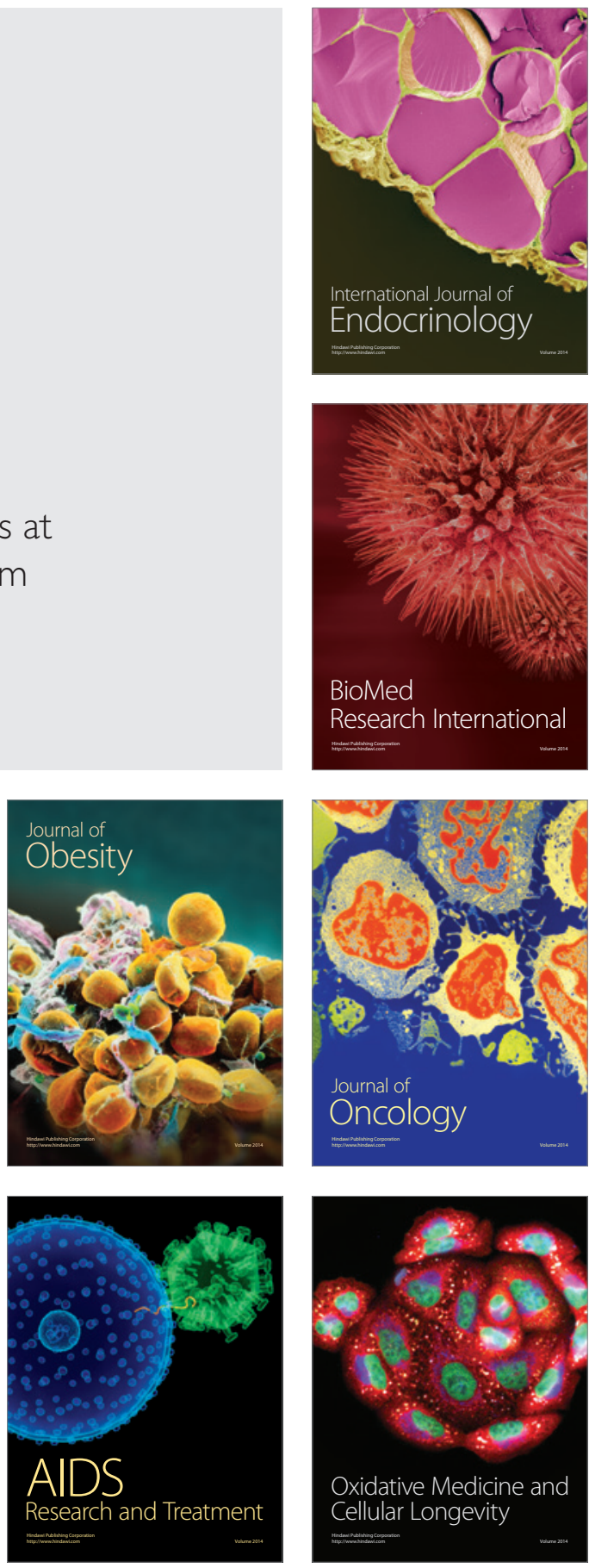